\title{
Enterprise Social Media (ESM) Use and Employee Belongingness in US Corporations
}

\author{
Phillip Melvin Randall ${ }^{1, *}$, Franklin Mister Lartey², Tywanda Dynel Tate ${ }^{3}$ \\ ${ }^{1}$ School of Business and Technology, Capella University, Minneapolis, the United States \\ ${ }^{2}$ Cox Communications, Inc., Atlanta, the United States \\ ${ }^{3}$ Prosperity Business Solutions Group, LLC, Mobile, the United States
}

Email address:

Phillip.Randall@capella.edu (P. M. Randall), franklin@lartey.net (F. M. Lartey),tdtate7@gmail.com (T. D. Tate)

${ }^{*}$ Corresponding author

\section{To cite this article:}

Phillip Melvin Randall, Franklin Mister Lartey, Tywanda Dynel Tate. Enterprise Social Media (ESM) Use and Employee Belongingness in US Corporations. Journal of Human Resource Management. Vol. 8, No. 3, 2020, pp. 115-124. doi: 10.11648/j.jhrm.201200803.12

Received: April 1,2020; Accepted: April 20, 2020; Published: April 28, 2020

\begin{abstract}
This study explored social capital theory by investigating the relationship between enterprise social media use (ESM) as measured by an adapted instrument and employee belongingness as measured by the balanced measure of psychological needs (BMPN) scale of employees in USA, moderated by generational age groups. A survey of 155 employees from US corporations was conducted. The results support the theoretical model of social capital as well as three hypothesized relationships. While there was no significant relation between Social-related ESM use and employee belongingness, there was a statistically significant relationship between Work-related ESM use, age generation groups, and employee belongingness. Overall, Generation-X employees showed a higher belongingness score compared to Millennials, and even higher compared to Generation- $Z$ employees. The results indicate that using an internal social media technology for work-related purposes can help employees feel that they belong and are a part of the social makeup of the organization. Work related social media use can also foster greater organizational social capital such as team building resulting in the achievement of organizational objectives and goals. These findings offer implications for research on social capital's value as an asset for the organization as well as enterprise social media's ongoing and ever-increasing value.
\end{abstract}

Keywords: Enterprise Social Media Use, Enterprise Social Networks, Employee Belongingness, Generational Differences, Social Capital

\section{Introduction}

After an overwhelmingly successful takeover of the public internet, enterprise social media (ESM) networks and associated platforms are quickly infiltrating and dominating internal communication networks and systems within organizations. Reportedly, their presence is said to improve communication and the capacity of the employee body to collaborate [21]. Albeit, despite increasing academic interest, research to date on the relationship between ESM use and the employee belongingness is both sparse and limited.

Enterprise Social Networking is part of a larger set of occurrences borne on the public Internet that are identified as social media, social software, and Web 2.0 [29]. The ability to facilitate user participation, interaction, and the generation of content by users are equally shared by components of all social media [4]. Social networking, blogs, wikis, and/or microblogging services are social media technologies that can be found throughout today's organizations [31]. The advent of this increasing usage can work to create organizational disfunction such as distrust, impaired team building, declining productivity.

In an interesting and mentionable contrast, a March 2019 poll jointly conducted by NBC News/Wall Street Journal (2019) reported a whopping 82 percent of those polled say social media sites do more to waste people's time than anything else. However, in the same poll nearly seven in 10 Americans (69 percent) say they use social media at least once a day.

Further, loneliness remains pervasive in societies where social media usage is highest [30]. In fact, Hunt, Marx, 
Lipson, and Young concluded in a 2018 study that depression and loneliness were primarily a causal link between the use of social media and negative effects on well-being. Additionally, fear of missing out, or FOMO, is another mental health effect that's been strongly linked with the use of social media. David M. Cordani, President and Chief Executive Officer, Cigna, said recently,

The trends shaping how we work - increasing use of technology, more telecommuting and the always-on work culture - are leaving Americans more stressed, less rested, spending more time on social media, and less time with friends and family. "For the business community, it is resulting in less engagement, less productivity and lower retention levels. To confront these issues at home and at work, we are helping people build stronger connections and driving deeper health engagement to improve overall well-being and vitality [8].

Given the broad framework introduced in the preceding that discusses the social media use experiences in both the private and the public domains, this research focused on Enterprise Social Media Networking (ESN), a set of technologies derived from social networking sites (SNS) such as Facebook, YouTube, Instagram, and Snapchat. SNS connect users by creating relationships and facilitating interactions between them through the exchange of short messages [4]. As defined, several technologies have emerged earmarked to address these very functions within organizations targeted exclusively at corporate users, namely Yammer, Tibbr, Sitrion, or IBM Lotus Connections. Reportedly, the prime reasoning for this effort to install dedicated workplace ESN services is to blunt and minimize the confidentiality and information security risks associated with their employees use of public SNS for workplace communication [12].

\section{Social Capital Theory}

According to Riemer, Finke, and Hovorka (2015), social capital is defined "as the value of social structures (such as social relationships and networks) for actors in the pursuit of their goals" (p. 4). Rothstein (2003) advanced the idea that the foundational underpinning of social capital theory is the combination of macro-sociological historical structures such as large-scale patterns and trends within the overall social structure and with micro-level causal mechanisms such as the everyday lives and experiences of people in smaller groups, their patterns of association and behaviors. The theory of social capital explores human interactions in terms of their implications and the effect of exchange and facilitates concepts such as social support, social integration, and social togetherness [32, 41]. Social capital itself is defined by Nahapiet and Ghoshal (1998) as, "The sum of the actual and potential resources embedded within, available through, and derived from the network of relationships possessed by an individual or social unit" (p. 243).

Requena (2003) defines social capital as the set of cooperative relationships between social actors that facilitate collective action and can be measured based on five dimensions: trust, social relations, commitment, communication and influence (pg. 331). Each of these descriptors suggest that relationships are interactions between humans and basic to the essence of their definition. That said, the various departments within an organization where these combinations of interactions are most manifest and essential are human resources and marketing.

\section{Enterprise Social Networks and Their Use}

As for the relationship between ESM use and belonginess, ESM systems present the structural component of social capital theory in that it provides for the actions of individuals involved in the daily execution of their common goals and objectives within the enterprise. Further, the structural component of the social capital theory is informed by and from the design and use of the ESM system. The assumption of the structural approach as advanced by Rothstein (2003) was established by the reliability and familiarity of the system to users. If users related well and perceived efficiency in the use of the ESM tool, structural social capital assumed the users would increase use and variation of the system [25]. Social capital assumes that individuals share information to gain the benefit of social interaction including influence, prestige, job advancement, etc. [40]. The connection between social capital theory and the conduct of this study is straightforward when considering the overarching role that enterprise social media plays in the establishment of social networks and social relationships within the enterprise [1]. Critical to and for this research study, a social relationship is the basic construct from which social capital is produced, and accordingly, social networks are collections of individuals and their mutual relationships [16, 27].

\section{Definition of Constructs}

\subsection{Enterprise Social Media}

Enterprise social media is defined as:

Web-based platforms that allow workers to (1) communicate messages with specific coworkers or broadcast messages to everyone in the organization; (2) explicitly indicate or implicitly reveal particular coworkers as communication partners; (3) post, edit, and sort text and files linked to themselves or others; and (4) view the messages, connections, text, and files communicated, posted, edited and sorted by anyone else in the organization at any time of their choosing [19].

Enterprise social media is a phenomenon used to replicate more broadly-based social media by offering similar components such as individual profiles, wikis, blogs, video/picture sharing, etc. ESM is a proprietary system that limits access for internal enterprise purposes only and are designed specifically for organizational use [6]. 


\subsection{Belongingness and/or Relatedness}

In 1954, Maslow stated that the concept of "belonging" was a key factor in Americans' mind-body wellness. Further, Maslow (1968) advanced in his hierarchy of needs placed belongingness as a step after the meeting of basics needs such as hunger and safety. Baumeister and Leary (1995) proposed that people have:

...a need to belong for two main features. First, people need frequent personal contacts or interaction with the other person. Ideally, these interactions would be affectively positive or pleasant, but it is mainly important that the majority be free from conflict and negative affect. Second, people need to perceive that there is an interpersonal bond or relationship marked by stability, affective concern, and continuation into the foreseeable future (p. 500).

Relatedness refers to the need for the sense of belonging and being connected to other people [35]. For this research study, belongingness is viewed as a relationship between an individual and group of people, while relatedness is viewed as a relationship between two people or one person and a group without necessary belonging.

\subsection{Moderating Role of Generational Age Groups}

Conceivably, enterprise and corporate success may well be both dependent and determined by the behavior of present and future generations. There is a paucity of research on generational differences as it relates to ESM use and belongingness. The behavior and generational differences can be instrumental to long term success of an organization, a closer look is warranted.

Generational differences are defined as variations in workrelated values, attitudes, personalities, leadership styles and employment decisions [42]. There are five generations in the workforce: Traditionalists, Baby Boomers, Generation X (Gen X), Millennials (also known as Generation Y), and Generation Z, who are just entering the workforce [3, 42]. Among these, Gen $X$ and Millennials are the predominant generations in the workforce, more so given that Baby Boomers continue to retire [5].

Although work-related values and desires for advancement are similar across generations, individual perspectives on how to achieve personal fulfillment, meaningful work, belonging, and engagement may differ between generational cohorts [20]. Further, Hoole and Bonnema (2015) reported that work is a main component of adult life, and a primary source of fulfillment and belonging. Albeit, there is limited information available on generational differences in general at work, and specifically, associated with enterprise social media use [28]. This study examined the differences of enterprise social media use across generational age groups.

\section{Data Analysis and Results}

\subsection{Research Questions}

The omnibus research question for this study asked:
Is there a statistically significant relationship between the use of Enterprise Social Media (ESM) (represented by workrelated ESM use and social-related ESM use) and the employees' sense of belongingness or affiliation to their enterprise?

This overarching question generated four main research questions and related hypothesis.

RQ 1: What is the relationship, if any, between Socialrelated ESM use and belongingness?

Null Hypothesis $1 \quad\left(\mathrm{H}_{0}\right)$ : There is no statistically significant relationship between Social-related ESM use and belongingness.

Hypothesis $1\left(\mathrm{H}_{\mathrm{A}}\right)$ : There is a statistically significant relationship between Social ESM use and belongingness.

RQ 2: What is the relationship, if any, between Workrelated ESM use and belongingness?

Null Hypothesis $2 \quad\left(\mathrm{H} 2_{0}\right)$ : There is no statistically significant relationship between Work-related ESM use and belongingness.

Hypothesis $2\left(\mathrm{H} 2_{\mathrm{A}}\right)$ : There is a statistically significant relationship between Work-related ESM use and belongingness.

RQ 3: What is the relationship, if any, between ESM use, age group, and belongingness?

Null Hypothesis $3\left(\mathrm{H}_{0}\right)$ : There is no statistically significant relationship between ESM use, age group, and belongingness.

Hypothesis $3\left(\mathrm{H} 3_{\mathrm{A}}\right)$ : There is a statistically significant relationship between ESM use, age group, and belongingness

RQ 4: Does the age group (Generation) of employees influence their sense of belongingness in the enterprise?

Null Hypothesis $4\left(\mathrm{H}_{0}\right)$ : There is no statistically significant difference between age group (Generation) of employees and their sense of belongingness in the enterprise.

Hypothesis $4\left(\mathrm{H}_{\mathrm{A}}\right)$ : There is a statistically significant difference between age group (Generation) of employees and their sense of belongingness in the enterprise.

\subsection{Sample and Sample Size}

Data were collected through an online survey of employees in US corporations. Of the total 293 online candidates who started the survey questionnaire, 62 were eliminated because they were either incomplete or done for testing purposes. Of the remaining 231 candidates, 72 were not included in the study's sample because of the way the candidates answered the survey questions. In fact, the study's questionnaire included reversely asked questions allowing for the control of the quality of answers. As such, any respondent who answered the same way to all questions or group of questions was removed from the collected sample due to the resulting inconsistencies. For example, a candidate should not have answered "frequently" to both questions: "At work, I successfully complete difficult tasks and projects" and "At work, I struggle to do something I should be good at." Of the remaining 159 respondents, 4 were eliminated because they originated outside the United States, leaving 155 participants constituting the sample size for this study. 
To confirm the validity of the sample size, a post-hoc analysis was conducted. The data analysis presented below includes the analysis of internal consistency and reliability of the survey instrument using a Cronbach Alpha test [11], the confirmation of the factor structure of collected data, the validation of the assumptions of multiple regression, and the presentation of a multiple regression models testing the hypothesis previously stated in order to answer the research questions.

\subsection{Post Hoc Statistical Power Analysis}

The statistical power analysis package GPower 3.1.7 suggested by Faul, Erdfelder, Lang, and Buchner (2007) was used in conducting a post hoc power analysis to determine the achieved power given the error probability $\alpha$, a sample size, and an effect size. The sample size of 155 was used for the power analysis along with two independent (predictor) variables as a baseline for the power equation. Using Cohen's (1977) recommendations on the effect sizes of small $\left(f^{2}\right.$ $=.02)$, medium $\left(f^{2}=.15\right)$, and large $\left(f^{2}=.35\right)$, the study considered an alpha level of $p<.05$ and 2 predictors.

The post hoc analysis computed a statistical power exceeding .99 for detecting medium to large effect sizes. Because Cohen (1992) suggests that adequate power is obtained for values above .80 , it was concluded that the sample size for this study was more than adequate for answering the research questions.

\subsection{Reliability of the Survey Instrument}

In investigating the relationship between Enterprise Social Media (ESM) use and employee belongingness and/or relatedness, an instrument was created from the adaptation of existing instruments [7, 15, 24]. A Cronbach Alpha test was performed to analyze the reliability and internal consistency of the survey instrument used against the data collected. Using SPSS' Analyze/Scale/Reliability function, the Cronbach alpha was computed on the 28-item questionnaire based on 155 responses. The results show an alpha coefficient of .93 . Such value indicates a high level of internal consistency and reliability of the collected dataset and allows for further analysis without variable reduction. As explained by Taber (2018), the rule of thumb followed by most authors is to have a minimum Cronbach Alpha value of .70 to consider an acceptable level of self-consistency in an instrument.

\subsection{Factor Analysis}

Prior to proceeding with further analysis, a factor analysis (FA) was conducted to ascertain the structure of the latent variables. The latent variables of the ESM-Use scale proposed in this study are WORK_ESM (work-related ESM score) and SOCIAL_ESM (social-related ESM score). The latent output variable of Employee Belongingness score derived from the Balanced Measure of Psychological Needs (BMPN), a validated instrument used in measuring needsatisfaction [36].

Bartlett's test of sphericity, which tests the overall significance of all the correlations within the correlation matrix was significant $\left(\chi^{2}(378)=3789.99, p<0.001\right)$, indicating that the relationship of correlations between each item was adequate. As such, it was appropriate to use factor analysis on the collected dataset. In addition, the KaiserMeyer-Olkin measure of sampling adequacy indicated that the strength of the relationships among variables was high $(K M O=.93)$. This statistic was higher than the suggested minimum of .6 (Field, 2013) hence, it was acceptable to proceed with factor analysis.

A Factor analysis was performed on the dataset collected from the 28-question instrument related to enterprise social media use and employee belongingness. This was done on SPSS version 24 by using the function Analyze/Dimension Reduction/Factor. The factor analysis was based on the Principal Component Analysis extraction method with a Promax (non-orthogonal) rotation.

An initial dimension reduction analysis was conducted to extract factors based on eigenvalues greater than 3 , an eigenvalue being a measure of how much of the variance of the observed variables is explained by a factor. In other words, any generated factor would be able to explain as much variance as any combined 3 of its total variables. The inflection points on the resulting scree plot suggested the presence of four factors. Further analyses were conducted to extract 3, 4, and 5 factors respectively. The optimal factor analysis yielded four factors as shown on Table 1. Tabachnick and Fidell (2013) suggested that factor loadings greater than .32 were acceptable for consideration. Using this minimum acceptable loading in the factor analysis option, the Rotated Factor Matrix produced four components.

The first factor as represented on Table 1 was labelled SOCIAL_ESM because it included all social related scores from the survey instrument. Even though one element (WR1_POST_UPDATES) loaded at .552 on this factor, it also loaded at .354 on the second factor. This item was retained on the second factor due to the relatively low weight difference and the fact that it answered the work-related question: "At work, I post updates on work projects." In addition, it fitted with the other work-related questions answered by the second factor.

The second factor as presented on Table 1 was labelled WORK_ESM because it included all work-related questions from the survey instrument besides WR6_CHAT which loaded on a different factor. This factor also loaded an item from the BMPN instrument namely BMPN7_COMPLETE_TASKS. This element was removed from the solution because it was not related to ESM-use and did not load with non- ESM factors. Another item, BMPN9_DO_WELL had a loading of .36 on this factor and .34 on a different factor. It was decided to leave it with the other factor because the difference was negligible and the elements in the other factor derived from the BMPN instrument like this one.

The third factor was labelled BELONGINGNESS as all its variables measured items related to the sense of belongingness. This factor also included a variable from work related activities, WR_CHAT, answering the question: "I chat with others while at work." Such inclusion is 
supported by literature as it suggests the existence of direct communication with others when an employee feels the sense of engagement and trust [39]. Finally, the fourth factor was labelled DISENGAGEMENT because all its questions measured the sense of a negative view of the work environment or negative work performance.

After the removal of BMPN7_COMPLETE_TASKS from the solution, another factor analysis was conducted and showed no change in the outcome as all items loaded the same way in their selected factors. An analysis of the correlation between the four factors showed a low correlation between DISENGAGEMENT and all the other factors as shown in Table 2. This factor was dropped from the rest of the study which focused on identifying the relationship between SOCIAL_ESM, WORK_ESM, and BELONGINGNESS. All three factors were computed as the sum of their subtending variables and used in answering the research questions.

\subsection{Assumptions of the Multiple Regression}

In the analysis of the relationship between enterprise social media use and employee belongingness, one dependent variable (DV) was identified and named BELONGINGNESS This was a latent variable representing the employees' sense of belongingness within the company where they worked. Two independent variables (IV) were identified and used, namely SOCIAL_ESM and WORK_ESM representing the work related and social related ESM scores respectively. Both independent variables were latent variables measured at a scale measurement level in SPSS and explained in more details in the previous sections. Besides the measurement level of the variables, the assumptions of multiple regression were tested as suggested by Tabachnick and Fidell (2013).

This study had two independent variables and 155 participants. The number of cases was well over the minimum of $104+2=106$ required [14, 37], thus fulfilling the requirement related to the ratio of cases to independent variables. A descriptive statistic of the z-score of all variables showed that all were within the -3.29 to 3.29 range. This confirmed that there was no univariate outlier in the dataset. There were also no missing values as all responses were validated during the data cleanup phase. Two test measures confirmed the normality of the dependent variable: the Shapiro-Wilk test showed a significance of .007 and the Kolmogorov-Smirnov test had a significance of .003 . Both tests had significances above .001 , suggesting that the outcome variable could be considered normally distributed and did not require transformation. The absence of multivariate outliers was confirmed using the Mahalanobis distance. The probability that a value from the chi-square distribution with 2 degrees of freedom (number of independent variables) would be less than the obtain Mahalanobis resulted in no value below .001, suggesting the absence of any multivariate outlier. The analysis confirmed the normality, linearity, homoscedasticity, and independence of residuals through a scatter plot of standardized residuals and standardized predicted values showing no value outside the -3 to 3 range. Additionally, the
P-P plot of standardized residuals confirmed the normal distribution of these residuals. Finally, all variance inflation factors (VIF) of the solution were below 10, suggesting that multicollinearity and singularity were not causes of concern.

\subsection{Results}

Using the functions Analyze/Descriptive statistics/Explore and Analyze/Regression/Linear on IBM SPSS, a standard multiple regression model was created to assess the ability to predict the dependent variable BELONGINGNESS using the independent variables SOCIAL_ESM and WORK_ESM. A significant regression equation was found $F(2,143)=34.74, p<.001$, as shown by the analysis of variance (ANOVA) test presented on Table 3. The null hypothesis of ANOVA was rejected, suggesting that there was a statistically significant effect of work and social use of enterprise social media (SOCIAL_ESM and WORK_ESM) on employee belongingness represented by the dependent variable BELONGINGNESS.

The summary of the resulting multiple regression model is shown on Table 4. As presented, the model was statistically significant $(p<.001)$ and had an $R^{2}$ of .32 , suggesting that the model could explain $32 \%$ of the variability in employees' perception of belongingness.

In the model predicting BELONGINGNESS from WORK_ESM and SOCIAL_ESM, the $p$-value or significance associated with SOCIAL_ESM $(p=.19)$ as shown on Table 5 was not significant $(p>.05)$. The corresponding $95 \%$ confidence interval of the standardized coefficient B included 0 , meaning that this variable could as well be zero. In other words, while the multiple-regression model was significant, SOCIAL_ESM did not significantly contribute in predicting the outcome variable.

In analyzing the relationship between ESM use and employee belongingness, the model previously created confirmed the existence of a relationship between work-related use of ESM and the employee's sense of belongingness. This was confirmed by the variable WORK_ESM that was statistically significant $(p<.001)$ in the model. The question to answer next was: "Does the age group of employees influence their sense of belongingness in the enterprise?"

To answer this question, the AGE variable was grouped into categories named GEN_Z, MILLENIALS, GEN_X, and BABY_BOOMERS. These corresponded to the options available to answer the age question in the survey questionnaire. A dummy or indicator variable was created in the dataset for each age group using the SPSS functions Transform / Recode into Different Variables and creating a variable with the value of 1 for individuals in the related group and 0 if the individual was not in the group. A multiple regression model was created, and Table 6 shows a summary of the model.

The model analyzing the influence of age on the relationship between ESM-use and belongingness was statistically significant $F(5,140)=16.03, p<.001$. As presented on Table 6 , the model had an $R^{2}$ of .36, suggesting that it could explain $36 \%$ of the variability in employees' perception of belongingness.

With four nominal variables composing AGE 
(BABY_BOOMERS, GEN_X, MILLENIALS, and GEN_Z), only three were loaded in the multiple regression model. The fourth variable GEN X was left out to be pivotal or reference variable for comparison against other variables' contributions. The new model thus included WORK_ESM which was statistically significant in the relationship between ESM use and BELONGINGNESS but excluded SOCIAL_ESM which was not statistically significant. It also included the age variables BABY_BOOMERS, MILLENIALS, and GEN_Z. The coefficients of the model are shown on Table 7.

As presented on Table 7, the results for BABY_BOOMERS $(p=.877)$ were not statistically significant $(p>.05)$ but those of
GEN_Z $(p=.03)$, MILLENIALS $(p=.01)$, and WORK_ESM $(p<.001)$ were all significant with $p<.05$.

The unstandardized coefficients showed that in relation to the reference variable GEN X, MILLENIALS realized 1.38 fewer units on the dependent variable BELONGINGNESS. Similarly, GEN_Z contributed 2.13 less units on their belongingness scores compared to GEN_X. Finally, BABY_BOOMERS realized a slightly lower unit contribution to belongingness as compared to GEN_X with a score lower by .11, but that was not statistically significant. Overall, Generation-X employees showed a higher belongingness score compared to Millennials, and even higher compared to Generation-Z employees.

\subsection{Tables}

Table 1. Pattern Matrix of the Factor Analysis.

\begin{tabular}{|c|c|c|c|c|}
\hline \multicolumn{5}{|l|}{ Pattern Matrix ${ }^{\mathrm{a}}$} \\
\hline & \multicolumn{4}{|c|}{ Component } \\
\hline & 1 & 2 & 3 & 4 \\
\hline SR7 SEARCH PROFILES & .969 & & & \\
\hline SR3_SEND_INVITE & .949 & & & \\
\hline SR9_NEWS & .941 & & & \\
\hline SR1_CREATE_GROUPS & .935 & & & \\
\hline SR8_VISIT_PROFILES & .914 & & & \\
\hline SR6_SEARCH_INVITE & .913 & & & \\
\hline SR2_JOIN_GROUPS & .903 & & & \\
\hline SR5_INTERACTIONS & .797 & & & \\
\hline SR4_ACCEPT_INVITE & .729 & & & \\
\hline WR1_POST_UPDATES & .552 & .354 & & \\
\hline WR5_ORG_FILES & & .866 & & \\
\hline WR8_UPLOAD_INFO_FUTURE & & .757 & & \\
\hline WR3_SHARE_ORG_INFO & & .717 & & \\
\hline WR2_SETUP_MEETINGS & .343 & .661 & & \\
\hline WR4_SHARE_POLICIES & & .622 & & \\
\hline WR9_SHARE_EXPERTISE & & .586 & & \\
\hline BMPN7 COMPLETE TASKS & & .547 & & \\
\hline WR7_ACCESS_EXPERTISE & & .508 & & \\
\hline BMPN9_DO_WELL & & .368 & .342 & \\
\hline BMPN1_SENSE_OF_CONTACT & & & .835 & \\
\hline BMPN5_INTIMAACY_TRUST & & & .831 & \\
\hline BMNP3_FEEL_CONNECTED & & & .770 & \\
\hline WR6_CHAT - & & & .544 & .358 \\
\hline BMPN10_FEEL_IMCOMPETENT & & & & .810 \\
\hline BMPN8_STRUGGLE & & & & .800 \\
\hline BMPN2_FEEL_LONELY & & & & .741 \\
\hline BMPN6 DISAGREEMENTS CONFLICTS & & & & .670 \\
\hline BMPN4_FEEL_UNAPPRECIATED & & .396 & & .664 \\
\hline
\end{tabular}

Note. Results of the Factor Analysis Depicting the 28 Questions of the Study and Their Loadings in Each of the 4 Factors Identified, After Suppressing Loadings That Were Lower Than .32.

Extraction Method: Principal Component Analysis.

Rotation Method: Promax with Kaiser Normalization.

${ }^{\text {a }}$ Rotation converged in 7 iterations.

Table 2. Factor Correlation Matrix.

\begin{tabular}{lllll}
\hline Component Correlation Matrix & & & \\
\hline Component & $\mathbf{1}$ & $\mathbf{2}$ & $\mathbf{3}$ & \\
\hline 1 & 1.000 & .618 & .458 & .277 \\
2 & .618 & 1.000 & .559 & .123 \\
3 & .458 & .559 & 1.000 & .049 \\
4 & .277 & .123 & .049 & 1.000 \\
\hline
\end{tabular}

Note. Correlation Matrix Between the Four Factors Identified. Factor 4 Shows a Low Correlation with the Other Factors, All <.30.

Extraction Method: Principal Component Analysis.

Rotation Method: Promax with Kaiser Normalization. 
Table 3. Analysis of Variance for the final model.

\begin{tabular}{lllllll}
\hline ANOVA $^{\mathbf{a}}$ & & & & & \\
\hline Model & & Sum of Squares & df & Mean Square & F & Sig. \\
\hline \multirow{2}{*}{1} & Regression & 607.458 & 2 & 303.729 & 34.741 & $.000^{\mathrm{b}}$ \\
& Residual & 1250.213 & 143 & 8.743 & & \\
& Total & 1857.671 & 145 & & & \\
\hline
\end{tabular}

Note. Analysis of Variance (ANOVA) Shows That the Resulting Model Was Significant F $(2,143)=34.74, \mathrm{p}<.001$.

${ }^{a}$ Dependent Variable: BELONGINGNESS.

bredictors: (Constant), SOCIAL_ESM, WORK_ESM.

Table 4. Multiple Regression Model.

\begin{tabular}{|c|c|c|c|c|c|c|c|c|c|}
\hline \multicolumn{10}{|c|}{ Model Summary $^{\mathbf{b}}$} \\
\hline \multirow[b]{2}{*}{ Model } & \multirow{2}{*}{$\mathbf{R}$} & \multirow{2}{*}{ R Square } & \multirow{2}{*}{$\begin{array}{l}\text { Adjusted R } \\
\text { Square } \\
\end{array}$} & \multirow{2}{*}{$\begin{array}{l}\text { Std. Error of } \\
\text { the Estimate }\end{array}$} & \multicolumn{5}{|l|}{ Change Statistics } \\
\hline & & & & & R Square Change & F Change & df1 & df2 & Sig. F Change \\
\hline 1 & $.572^{\mathrm{a}}$ & .327 & .318 & 2.95681 & .327 & 34.741 & 2 & 143 & .000 \\
\hline
\end{tabular}

Note. Model Summary Showing an $\mathrm{R}^{2}$ of $.32, \mathrm{p}<.001$.

${ }^{a}$ Predictors: (Constant), SOCIAL_ESM, WORK_ESM.

${ }^{b}$ Dependent Variable: BELONGINGNESS.

Table 5. Coefficients of the Regression Model.

\begin{tabular}{|c|c|c|c|c|c|c|c|c|c|c|}
\hline \multicolumn{11}{|c|}{ Coefficients $^{\mathrm{a}}$} \\
\hline \multirow{2}{*}{\multicolumn{2}{|c|}{ Model }} & \multicolumn{2}{|c|}{$\begin{array}{l}\text { Unstandardized } \\
\text { Coefficients }\end{array}$} & \multirow{2}{*}{$\begin{array}{l}\text { Standardized } \\
\text { Coefficients } \\
\text { Beta }\end{array}$} & \multirow[b]{2}{*}{$\mathbf{t}$} & \multirow{2}{*}{ Sig. } & \multicolumn{2}{|c|}{$\begin{array}{l}95.0 \% \text { Confidence Interval } \\
\text { for B }\end{array}$} & \multicolumn{2}{|c|}{$\begin{array}{l}\text { Collinearity } \\
\text { Statistics }\end{array}$} \\
\hline & & B & Std. Error & & & & $\begin{array}{l}\text { Lower } \\
\text { Bound }\end{array}$ & $\begin{array}{l}\text { Upper } \\
\text { Bound }\end{array}$ & Tolerance & VIF \\
\hline \multirow{3}{*}{1} & (Constant) & 11.868 & .878 & & 13.520 & .000 & 10.133 & 13.603 & & \\
\hline & WORK_ESM & .232 & .050 & .470 & 4.683 & .000 & .134 & .330 & .467 & 2.143 \\
\hline & SOCIAL_ESM & .036 & .028 & .130 & 1.291 & .199 & -.019 & .091 & .467 & 2.143 \\
\hline
\end{tabular}

Note. Coefficients of the Model Showed That WORK_ESM Was Statistically Significant $(\mathrm{p}<.05)$ While SOCIAL_ESM Was Not ( $p>.05)$.

${ }^{a}$ Dependent Variable: BELONGINGNESS.

Table 6. Summary of the Regression Model Analyzing the Influence of AGE.

\begin{tabular}{lllll}
\hline Model Summary $^{\mathbf{b}}$ & & & \\
\hline Model & R & R Square & Adjusted R Square & Std. Error of the Estimate \\
\hline 1 & $.602^{\mathrm{a}}$ & .363 & .345 & 2.89754 \\
\hline
\end{tabular}

Note. The Summary of the Model Analyzing the Influence of Age on the Relationship Between ESM Use and the Sense of Belongingness Shows an $\mathrm{R}^{2}$ of .36, an Increase of 4 Compared to the Model Without Age.

${ }^{a}$ Predictors: (Constant), BABY_BOOMERS, WORK_ESM, GEN_Z, MILLENIALS.

bependent Variable: BELONGINGNESS.

Table 7. Coefficients of the Regression Model.

\begin{tabular}{|c|c|c|c|c|c|c|c|c|}
\hline \multicolumn{9}{|c|}{ Coefficients $^{\mathrm{a}}$} \\
\hline \multirow{2}{*}{\multicolumn{2}{|c|}{ Model }} & \multicolumn{2}{|c|}{ Unstandardized Coefficients } & \multirow{2}{*}{$\begin{array}{l}\text { Standardized Coefficients } \\
\text { Beta } \\
\end{array}$} & \multirow[b]{2}{*}{ t } & \multirow{2}{*}{ Sig. } & \multicolumn{2}{|c|}{ 95.0\% Confidence Interval for B } \\
\hline & & B & Std. Error & & & & Lower Bound & Upper Bound \\
\hline \multirow{5}{*}{1} & (Constant) & 12.121 & .884 & & 13.711 & .000 & 10.373 & 13.869 \\
\hline & WORK_ESM & .292 & .034 & .592 & 8.718 & .000 & .226 & .359 \\
\hline & GEN_Z & -2.130 & .999 & -.151 & -2.133 & .035 & -4.104 & -.156 \\
\hline & MILLENIALS & -1.383 & .546 & -.191 & -2.533 & .012 & -2.463 & -.304 \\
\hline & BABY BOOMERS & -.116 & .745 & -.011 & -.155 & .877 & -1.589 & 1.358 \\
\hline
\end{tabular}

Note. Coefficients of the Model with the Age Showed That All but the BABY_BOOMERS' Scores Were Statistically Significant ( $<<.05)$.

${ }^{a}$ Dependent Variable: BELONGINGNESS.

\section{Discussion and Practical Implications}

The purpose of this enterprise social media use study was to investigate if enterprise (internal) social media use can facilitate employee belongingness and/or relatedness which may enhance or results in the development of organizational social capital. The study also considered the age generational differences in the use of enterprise social media. To this end, 155 employees who worked for US corporations were surveyed.

The results support the social capital theoretical model and support three hypothesized relationships. That is, there was a statistically significant relationship between ESM use and belongingness. While there was no significant relationship between social-related (ESM) and employee belongingness, 
there was a statistically significant relationship between work-related ESM use, age generation groups, and employee belongingness.

Overall, Generation-X employees showed a higher belongingness score compared to Millennials, and even higher compared to Generation-Z employees. The results indicate that using an internal social media technology for work-related purposes can help employees feel that they belong and are a part of the social makeup of the organization. Work-related social media use can also foster greater organizational social capital such as team building, trust, social relations, commitment, communication, and influence [32]. This combination of benefits may result in the achievement of organizational objectives and goals [33]. These findings offer implications for research on social capital's value as an asset for the organization as well as enterprise social media's ongoing and ever-increasing value.

\section{Limitations}

While this research made significant contributions, it's findings should not be generalized without considering some identified limitations.

The study used a self-administered survey questionnaire and participants could answer without any possibility of following up to understand the reason for their choices. With the incentives offered by the surveying company for completed questionnaires, some participants provided the same answers regardless of the question asked in order to take credit for the completed survey. Even though our questions were structured in a way that allowed us to identify such participants and eliminate their answers from the final sample, some could still have made it through.

Another limitation relates to the definition of enterprise social media (ESM) that seemed ambiguous to some participants. While a definition was provided on the survey questionnaire, some participants could very well have difficulties understanding the differences between an ESM and computer applications such as word processors, spreadsheets, and emails. In such cases, their answers would be addressing a different concept from that being studied.

Finally, this study was conducted in the United States of America and its findings should not be generalized to other countries. As a special note in considering the results associated with the age generations, the sample size of 155 was sufficient to test our hypotheses, however, when divided by age generations, may well have been too small for significant differences to be observed [15]. Additionally, as noted, company size or industry was not considered. A replication of this study could be conducted in other countries to confirm the current findings thus allowing for generalization.

\section{Conclusion}

In researching the relationship between enterprise social media (ESM) use and employee belongingness, this study confirmed the existence of a relationship between workrelated use of ESM and employee belongingness. It also confirmed that Generation X employees scored higher in belongingness as compared to Generation $\mathrm{Z}$ employees who in turn scored higher compared to Millennials. With the increasing presence of social media technology in organizations, further investigations on how work and socialrelated enterprise social media use looms as increasingly important to organizational success. Further, the need to understand the implication of enterprise social media usage by the different age generations residing in the organizations is also clearly a necessity for current and future organizational effectiveness. The question of employee belongingness and the advent of individual loneliness associated with an ever-growing preoccupation with social media technology inside and outside of the organization argues for more research on each of these beforementioned constructs and their importance to the well-being of individuals, the organization, and our community.

\section{References}

[1] Anders, A. (2016). Team communication platforms and emergent social collaboration practices. International Journal of Business Communication, 53 (2), 224-261. DOI: $10.1177 / 2329488415627273$.

[2] Baumeister, R. F., \& Leary, M. R. (1995). The need to belong: Desire for interpersonal attachments as a fundamental human motivation. Psychological Bulletin, 117 (3), 497-529. DOI: 10.1037/0033-2909.117.3.497.

[3] Bencsik, A., Horváth-Csikós, G., \& Juhász, T. (2016). Y and Z generations at workplaces. Journal of Competitiveness, 6 (3), 90-106. DOI: 10.7441/joc.2016.03.06.

[4] Boyd, dm, \& Ellison, N. B. (2007). Social network sites: Definition, history, and scholarship. Journal of ComputerMediated Communication, 13 (1), 210-230. DOI: 10.1111/j.1083-6101.2007.00393.x.

[5] Campbell, W. K., Campbell, S. M., Siedor, L. E., \& Twenge, J. M. (2015). Generational differences are real and useful. Industrial and Organizational Psychology, 8 (3), 324-331. DOI: $10.1017 /$ iop.2015.43.

[6] Cardon, P. W., \& Marshall, B. (2015). The hype and reality of social media use for work collaboration and team communication. International Journal of Business $\begin{array}{lccr}\text { Communication, } & 52 & \text { (3), 273-293. } & \text { DOI: }\end{array}$ $10.1177 / 2329488414525446$.

[7] Chen, A., Lu, Y., Chau, P. Y. K., \& Gupta, S. (2014). Classifying, measuring, and predicting users' overall active behavior on social networking sites. Journal of Management Information Systems, 31 (3), 213-253. DOI: 10.1080/07421222.2014.995557.

[8] Cigna Newsroom (23 January 2020). Cigna takes action to combat the rise of loneliness and improve mental wellness in America. https://www.multivu.com/players/English/8670451cigna-2020-loneliness-index/ 
[9] Cohen, J. (1977). Statistical power analysis for the behavioral sciences (rev. edn.). Hillsdale, NJ: Lawrence Erlbaum Associates, Inc.

[10] Cohen, J. (1992). A power primer. Psychological Bulletin, 112 (1), 155-159. DOI: 10.1037//0033-2909.112.1.155.

[11] Cronbach, L. J. (1951). Coefficient alpha and the internal structure of tests. Psychometrika, 16 (3), 297-334. DOI: $10.1007 / \mathrm{bf02310555.}$

[12] DiMicco, J., Millen, D., Geyer, W., \& Dugan, C. (2008). Research on the use of social software in the workplace. Cambridge, MA: IBM Research.

[13] Faul, F., Erdfelder, E., Lang, A. G., \& Buchner, A. (2007). G*Power 3: A flexible statistical power analysis program for the social, behavioral, and biomedical sciences. Behavior Research Methods, 39 (2), 175-191. DOI: 10.3758/bf03193146.

[14] Field, A. (2013). Discovering statistics using IBM SPSS Statistics (fourth edn.). Thousand Oaks, CA: SAGE Publications.

[15] Gonzalez, E. S., Leidner, D. E., Riemenschneider, C., \& Koch, H. (2013). The impact of internal social media usage on organizational socialization and commitment. International Conference on Information Systems (ICIS), Milan, Italy.

[16] Granovotter, M., \& Swedberg, R. (1992). The sociology of economic life. Boulder, CO: Westview Press.

[17] Hoole, C., \& Bonnema, J. (2015). Work engagement and meaningful work across generational cohorts. SA Journal of Human Resource Management, 13 (1), 1-e11. DOI: 10.4102/sajhrm.v13i1.681.

[18] Hunt, M. G., Marx, R., Lipson, C., \& Young, J. (2018). No more FOMO: Limiting social media decreases loneliness and depression. Journal of Social and Clinical Psychology, 37 (10), 751-768. DOI: 10.1521/jscp.2018.37.10.751.

[19] Leonardi, P. M., Huysman, M., \& Steinfield, C. (2013). Enterprise Social Media: Definition, history, and prospects for the study of social technologies in organizations. Journal of Computer-Mediated Communication, 19 (1), 1-19. DOI: 10.1111/jcc4.12029.

[20] Lips-Wiersma, M., \& Wright, S. (2012). Measuring the meaning of meaningful work: Development and validation of the comprehensive meaningful work scale (CMWS). Group and Organization Management, 37 (5), 655-685. DOI: $10.1177 / 1059601112461578$.

[21] Mäntymäki, M., \& Riemer, K. (2014). The value of enterprise social networks. 25th Australasian Conference on Information Systems, December 8-10, 2014, Auckland, New Zealand.

[22] Maslow, A. H. (1954). Motivation and personality. New York: Harper \& Row.

[23] Maslow, A. H. (1968). Toward a psychology of being. New York: Van Nostrand.

[24] Moqbel, M., \& Fui-Hoon Nah, F. (2017). Enterprise social media use and impact on performance: The role of workplace integration and positive emotions. AIS Transactions on Human-Computer Interaction, 9 (4), 261-280. DOI: 10.17705/1thci.00098.

[25] Nahapiet, J., \& Ghoshal, S. (1998). Social capital, intellectual capital, and the organizational advantage. The Academy of Management Review, 23 (2), 242-266. DOI:

\subsection{5/AMR.1998.533225.}

[26] NBC News/Wall Street Journal Poll, March 23-27, 2019. https://www.insider.com/majority-of-americans-are-fed-upwith-social-media-platforms-2019-4

[27] Newman, M. E. J. (2003). The structure and function of complex networks. SIAM Review, 45 (2), 167-256. DOI: $10.1137 / \mathrm{S} 003614450342480$.

[28] Oh E., \& Reeves, T. C. (2014). Generational differences and the integration of technology in learning, instruction, and performance. In: Spector J., Merrill M., Elen J., Bishop M. (eds) Handbook of Research on Educational Communications and Technology (pp 819-828). Springer, New York, NY.

[29] O'Reilly, T. (2009). What is Web 2.0. O'Reilly Media, Inc.

[30] Pittman, M., \& Reich, B. (2016). Social media and loneliness: Why an Instagram picture may be worth more than a thousand Twitter words. Computers in Human Behavior, 62 (September), 155-167. DOI: 10.1016/j.chb.2016.03.084.

[31] Razmerita, L., Kirchner, K., \& Nabeth, T. (2014). Social media in organizations: Leveraging personal and collective knowledge processes. Journal of Organizational Computing and Electronic Commerce, 24 (1), 74-93. DOI: 10.1080/10919392.2014.866504.

[32] Requena, F. (2003). Social capital, satisfaction and quality of life in the workplace. Social Indicators Research 61, 331-360. DOI: 10.1023/A:1021923520951.

[33] Riemer, K., Finke, J., \& Hovorka, D. (2015). Bridging or bonding: Do individuals gain social capital from participation in enterprise social networks? Social Capital in Enterprise Social Networks, 36th International Conference on Information Systems, Fort Worth, TX.

[34] Rothstein, B. (2003). Social capital, economic growth and quality of government: the causal mechanism. New Political Economy, 8 (1), 49-71, DOI: 10.1080/1356346032000078723.

[35] Ryan, R., \& Deci, E. L. (2000). The "what" and "why" of goal pursuits: Human needs and the self-determination of behavior. Psychological Inquiry, 11 (4), 227-268. DOI: 10.1207/S15327965PLI1104_01.

[36] Sheldon, K. M., \& Hilpert, J. C. (2012). The balanced measure of psychological needs (BMPN) scale: An alternative domain general measure of need satisfaction. Motivation and Emotion, 36 (4), 439-451. DOI: 10.1007/s11031-012-9279-4.

[37] Tabachnick, B. G., \& Fidell, L. S. (2013). Using multivariate statistics (sixth edn.). Upper Saddle River, NJ: Pearson.

[38] Taber, K. S. (2018). The use of Cronbach's alpha when developing and reporting research instruments in science education. Research in Science Education, 48 (6), 1273-1296. DOI: $10.1007 / \mathrm{s} 11165-016-9602-2$.

[39] Tate, T. D., Lartey, F. M., \& Randall, P. M. (2019). Relationship between computer-mediated communication and employee engagement among telecommuting knowledge workers. Journal of Human Resource and Sustainability Studies, 7 (2), 328-347. DOI: 10.4236/jhrss.2019.72021.

[40] Taylor, S. (2007). Creating social capital in MNCs: The international human resource management challenge. Human Resource Management Journal, 17 (4), 336-354. DOI: 10.1111/j.1748-8583.2007.00049.x. 
[41] Warren, A. M., Sulaiman, A., \& Jaafar, N. I. (2015). Understanding civic engagement behaviour on Facebook from a social capital theory perspective. Behaviour \& Information Technology, $\quad 34 \quad$ (2), 163-175. doi: 10.1080/0144929X.2014.934290.
[42] Weeks, K. P., \& Schaffert, C. (2019). Generational differences in definitions of meaningful work: A mixed methods study. Journal of Business Ethics, 156 (4), 1045-1061. DOI: 10.1007/s10551-017-3621-4.

\section{Biography}

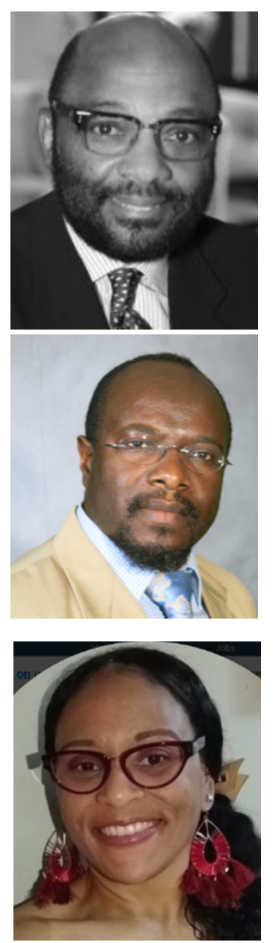

Phillip Melvin Randall, PhD, CPG, is currently the Managing Partner, The Thorndyke Group, a human capital consultancy specializing in individual and organizational effectiveness, Atlanta, GA; Faculty member, School of Business and Technology, Capella University, Minneapolis, MN; and member, Board of Governors, Accreditation for Gerontology Education Council. He received his BA from the Youngstown State University, Youngstown, Ohio; MS from the University of Michigan, Ann Arbor, MI; and a PhD from The University of Akron, Akron, OH. He earned a Specialist in Aging certification from the Institute of Gerontology, University of Michigan and Wayne State University, Ann Arbor, MI.

Franklin Mister Lartey obtained his $\mathrm{PhD}$ with honors from Capella University. He also holds an MBA in Finance with a 4.0 GPA from Baker University in Kansas and an MS in Computer Engineering from the African Institute of Computer Engineering in Gabon. In addition to his academic achievements, Dr. Lartey also holds various professional certifications among which: Cisco CCNP, CCDP, CCNA; Microsoft MCSE, MCDBA, MCP; Comptia A+, Network+, Security + , and many others. After working with the United Nations, the World Bank, and the U.S. State Department, Dr. Lartey is currently Director of Technology in charge of Planning and Forecasting at Cox Communications, one of the largest providers of cable and telecommunication services in the US.

Tywanda Dynel Tate earned her PhD with honors and MBA with a specialization in Human Resource Management from Capella University. She is a member of Delta Mu Delta, International Honor Society in Business, XI Delta Chapter, Capella University. She received her BS and MS from Faulkner University, Montgomery, AL. Dr. Tate is currently the owner of Prosperity Business Solutions Group, LLC, a business management and operations consulting firm, Mobile, AL. 